\title{
Short Communication \\ Birth weight in relation to endometrial and breast cancer risks in Swedish women
}

\author{
M Löf',*, S Sandin', L Hilakivi-Clarke ${ }^{2}$ and E Weiderpass ${ }^{1,3}$ \\ 'Department of Medical Epidemiology and Biostatistics, Karolinska Institute, PO 281, SE-17I 77, Stockholm, Sweden; ${ }^{2}$ Department of Oncology, \\ Georgetown University, Washington, DC 20057, USA; ${ }^{3}$ The Cancer Registry of Norway, N-0310, Montebello, Oslo, Norway
}

\begin{abstract}
An examination of birth weight in a Swedish cohort study of 38566 women showed no significant association between birth weight and endometrial cancer, but supported a protective role for low birth weight for premenopausal breast cancer. British Journal of Cancer (2007) 96, I34- 136. doi: I0.1038/sj.bjc.6603504 www.bjcancer.com

Published online 5 December 2006

(c) 2007 Cancer Research UK
\end{abstract}

Keywords: endometrial cancer; breast cancer; birth weight

Evidence for a positive association between birth weight and risk of adult hormone-dependent cancers is limited primarily to breast cancer. Only one study has investigated whether there is an association between birth weight and endometrial cancer (McCormack et al, 2005). During a follow-up of 41 years, women with higher birth weights had a reduced risk of endometrial cancer (McCormack et al, 2005). Although current evidence strongly suggests that high birth weight increases premenopausal breast cancer risk (Michels and Xue, 2006), several of these studies investigated women born in the 1910-1940s (Andersson et al, 2001; Titus-Ernstoff et al, 2002; dos Santos Silva et al, 2004; McCormack et al, 2005). These women were born and grew up during or just after World War I and II, when their nutritional status in utero and during childhood was probably different from that among women born later. Further, the role for low birth weight for breast cancer risk is not fully worked out. Adjustment for adult body mass index (BMI) is highly relevant, as it is associated with birth weight (Oken and Gillman, 2003) and also affects adult breast cancer risk (Huang et al, 1997). Also, adult BMI is a strong risk factor for endometrial cancer (Amant et al, 2005). We have investigated whether low birth weight is associated with endometrial and breast cancer risks in a prospective cohort of Swedish women born during 1942-1962, adjusting for adult BMI.

\section{MATERIALS AND METHODS}

The study cohort consisted of 49259 Swedish women in the Women's Lifestyle and Health study (Kumle et al, 2002). The mean age at baseline in 1991 was 39 years and $9 \%$ of the women were postmenopausal. Participants reported weight and height at enrolment, and their own birth weight $(<2.5 \mathrm{~kg}, 2.5-3 \mathrm{~kg}$, or $>3 \mathrm{~kg}$ ) using a questionnaire. Complete follow-up was achieved from linkages with nationwide health registers through December 2003, yielding 73 cases of endometrial cancer, and 657 cases of

*Correspondence: Dr M Löf; E-mail: marie.lof@ki.se

Received II September 2006; revised 30 October 2006; accepted 3 November 2006; published online 5 December 2006 breast cancer. We excluded 10693 women from the initial cohort because of: breast or endometrial cancer before enrolment ( $n=253)$, emigration before the start of the follow-up $(n=16)$, hysterectomy $(n=1501)$, twins $(n=1154)$, and with missing information on birth weight or adult BMI $(n=7769)$. Thus, the final analysis was conducted on 38566 women. The study was approved by the ethical committee at the University of Uppsala and the Karolinska Institute.

The risks of endometrial and breast cancers were analysed by fitting of Cox regression models. One crude model including only the birth weight variable was fitted for both endometrial and breast cancer. A second model including BMI at enrolment was fitted for both cancer forms. We also fitted models including the following covariates: parity, age at first birth, total months of breastfeeding, and family history of breast cancer (mother or sister). For all models, the attained age at follow-up was used as time scale and stratified by 5-year birth cohorts. Hazard ratios (HR) were declared statistically significant when the associated two-sided 95\% Wald-type confidence interval did not cover the value one. This corresponds to a two-sided 5\% level of significance. All statistical analyses were carried out using the SAS software version 9.1, (SAS Institute Inc., Cary, NC, USA).

\section{RESULTS}

The baseline characteristics of the 38566 women in this study are presented in Table 1. Thus, 5\% (1975) of the 38566 women reported birth weights $<2.5 \mathrm{~kg}$, whereas $20 \%$ (7877) and $75 \%$ (28 714) reported birth weights $2.5-3 \mathrm{~kg}$ and $>3 \mathrm{~kg}$, respectively. Five per cent (four) of the endometrial cancer cases reported birth weights $<2.5 \mathrm{~kg}$, whereas $15 \%$ (11) reported birth weights $2.5-$ $3 \mathrm{~kg}$, and $80 \%$ (58) reported birth weights $>3 \mathrm{~kg}$. The corresponding figures for the breast cancer cases were $4 \%$ (23), $22 \%$ (144), and $74 \%(490)$ for birth weights $<2.5 \mathrm{~kg}, 2.5-3 \mathrm{~kg}$, and $>3 \mathrm{~kg}$, respectively. Fifty-six per cent (41) of the endometrial cancer cases were normal weight $\left(\mathrm{BMI}<25 \mathrm{~kg} / \mathrm{m}^{2}\right)$, whereas $28 \%$ (20) were overweight (BMI $\left.25-30 \mathrm{~kg} / \mathrm{m}^{2}\right)$, and $16 \%$ (12) were obese ( $\geqslant 30 \mathrm{~kg} /$ $\mathrm{m}^{2}$ ). The corresponding figures for the breast cancer cases were: $76 \%$ (501) normal weight, 19\% (123) overweight, and 5\% (33) 
obese. When compared to the 38566 women who were included in the analysis, the distribution of the baseline characteristics were similar for the 7769 women who were excluded from the study owing to missing values of birth weight or adult BMI (data not shown).

Table I Baseline characteristics of the women of the study $(n=38566)$

\begin{tabular}{|c|c|c|c|}
\hline & \multicolumn{3}{|c|}{ Birth weight (kg) } \\
\hline & $<2.5(n=1975)$ & $2.5-3(n=7877)$ & $>3(n=287 \mid 4)$ \\
\hline \multicolumn{4}{|c|}{ BMl at enrolment $\left(\mathrm{kg} / \mathrm{m}^{2}\right)$} \\
\hline Median & 23 & 23 & 23 \\
\hline Quartile I & 21 & 21 & 21 \\
\hline Quartile 3 & 25 & 25 & 25 \\
\hline Range & $16-48$ & $15-67$ & $13-65$ \\
\hline \multicolumn{4}{|c|}{ Age at enrolment (years) } \\
\hline Median & 39 & 39 & 38 \\
\hline Quartile I & 34 & 34 & 34 \\
\hline Quartile 3 & 44 & 44 & 43 \\
\hline Range & $29-49$ & $29-49$ & $29-49$ \\
\hline Parity at enrolment & \multicolumn{3}{|c|}{ Number of women (\%) } \\
\hline 0 & $328(17)$ & $1177(15)$ & $3783(13)$ \\
\hline 1 & $279(14)$ & $1276(16)$ & $4365(15)$ \\
\hline 2 & 843 (43) & 3334 (42) & 12555 (44) \\
\hline 3 & $383(19)$ & $|56|(20)$ & $6127(21)$ \\
\hline$\geqslant 4$ & $142(7)$ & $529(7)$ & $1884(7)$ \\
\hline
\end{tabular}

The HR for endometrial and breast cancer risk for different birth weight categories are shown in Figure 1. The crude HR for endometrial cancer risk for women with low birth weight $(<2.5 \mathrm{~kg})$ compared to women with normal to high birth weight ( $>3 \mathrm{~kg}$ ) was 0.6 , and not statistically significant. Adjusting for adult BMI did not modify the HR. The adjusted model also provided HR estimates for endometrial cancer risk for different BMI categories (BMI $<25$, BMI $25-30$, and BMI $\geqslant 30 \mathrm{~kg} / \mathrm{m}^{2}$ ). Obese women $\left(\mathrm{BMI} \geqslant 30 \mathrm{~kg} / \mathrm{m}^{2}\right)$ had a statistically significant increased risk of endometrial cancer (HR: 3.1, 95\% CI: 1.6-5.8) compared to normal weight women (BMI $<25)$.

The crude HR for breast cancer risk, when comparing women with low birth weight $(<2.5 \mathrm{~kg})$ to women with the highest birth weight ( $>3 \mathrm{~kg}$ ) was 0.65 (95\% CI: $0.43-0.99$ ). The results were not affected by adjustment for adult BMI.

The HR for endometrial and breast cancer reported in Figure 1 were not affected by adjustment for other baseline covariates like parity, age at first birth, total months of breastfeeding, or family history of breast cancer (mother or sister) (data not shown).

\section{DISCUSSION}

We found no evidence of an association between low birth weight, and reduced endometrial cancer risk, although our data supported earlier findings that a higher birth weight increases breast cancer risk. The results also suggest that low birth weight is protective for breast cancer. Adult BMI did not modify the effect of a low birth weight on endometrial or breast cancer risk.

Strengths of this study are the prospective design, and the complete follow-up. One major limitation is that we only had three

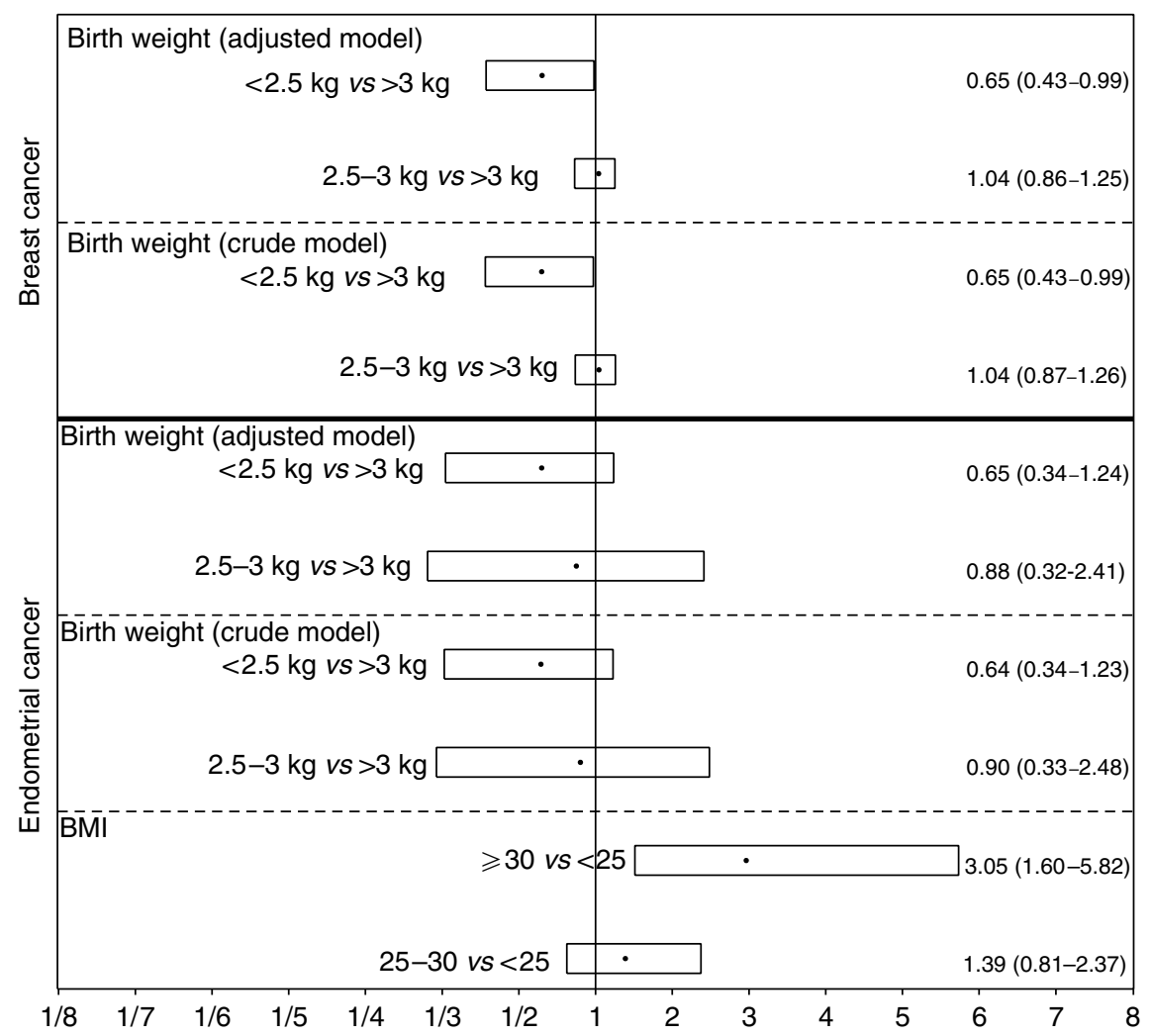

Figure I Estimated HR (black dots) with associated two-sided 95\% Wald confidence intervals (boxes) for comparison of two categories, for example women with a birth weight $<2.5 \mathrm{~kg}$ compared to women with a birth weight $>3 \mathrm{~kg}$. The adjusted model for both breast and endometrial cancer include the covariates birth weight $(<2.5 \mathrm{~kg}, 2.5-3 \mathrm{~kg}$ and $>3 \mathrm{~kg})$ and adult BMI $\left(<25,25-30\right.$ and $\left.\geqslant 30 \mathrm{~kg} / \mathrm{m}^{2}\right)$ both as categorical covariates. Additionally, the HR estimates for endometrial cancer risk for normal weight women $(\mathrm{BMl}<25)$ compared to overweight women $(\mathrm{BMI} 25-30)$ and obese women $(\mathrm{BMI} \geqslant 30)$, respectively, provided by the adjusted model are shown. All models were fitted stratified by 5 -year birth cohorts utilising attained age as time scale. 
categories of birth weight, and the highest category included infants of normal as well as of high birth weight. Earlier studies have suggested that birth weights above $4000 \mathrm{~g}$ increase breast cancer risk (Sanderson et al, 1996; McCormack et al, 2003, 2005; Mellemkjaer et al, 2003; Ahlgren et al, 2004; dos Santos Silva et al, 2004), while increased (Innes et al, 2000; Mellemkjaer et al, 2003), or reduced (Michels et al, 1996; Michels et al, 2006) risks have been reported for low birth weight. Results of this study indicate that among women born in the 1940-1960s, a low birth weight is associated with reduced breast cancer risk. The results suggest that the earlier reported link between birth weight, and breast cancer in women born in the early 1900s is also relevant for women born in the mid-1900s.

Another limitation of the study was that we could not adjust for gestational age, which has been shown to strengthen the positive association between birth weight and breast cancer risk (McCormack et al, 2003). Some misclassification of birth weight (Troy et al, 1996; Andersson et al, 2000) is unavoidable but likely nondifferential and thus, would have led to an underestimation of the true association.

The inconsistency between this study and the only other study on endometrial cancer (McCormack et al, 2005) may be due to the small number of cases in both. Still, although we had only 73 cases we were able to confirm earlier findings that obesity increases endometrial cancer risk (Amant et al, 2005). Other possible explanations include that women in our study were born approximately 30 years later than women in the study by McCormack et al (2005), our women were younger than 50 years of age, whereas their women were mostly postmenopausal, or that we focused on investigating the effect of a low birth weight, while they examined the impact of a high birth weight on endometrial cancer.

In conclusion, no association between birth weight and endometrial cancer risk was found, whereas a low birth weight was suggested to reduce the risk of developing breast cancer among women born in the 1940-1960s.

\section{ACKNOWLEDGEMENTS}

This work was supported by the grants obtained from the National Cancer Institute (1 U54 CA00100971, 5 RO1 CA89950) and Department of Defence (USAMRMC 00000100093).

\section{REFERENCES}

Ahlgren M, Melbye M, Wohlfahrt J, Sorensen TI (2004) Growth patterns and the risk of breast cancer in women. N Engl J Med 351: 1619-1626

Amant F, Moerman P, Neven P, Timmerman D, Van Limbergen E, Vergote I (2005) Endometrial cancer. Lancet 366: 491 - 505

Andersson SW, Bengtsson C, Hallberg L, Lapidus L, Niklasson A, Wallgren A, Hulthen L (2001) Cancer risk in Swedish women: the relation to size at birth. Br J Cancer 84: 1193-1198

Andersson SW, Niklasson A, Lapidus L, Hallberg L, Bengtsson C, Hulthen L (2000) Poor agreement between self-reported birth weight and birth weight from original records in adult women. Am J Epidemiol 152: 609-616

dos Santos Silva I, Stavola BL, Hardy R, Kuh D, McCormack VA, Wadsworth M (2004) Is the association of birth weight with premenopausal breast cancer risk mediated through childhood growth? $\mathrm{Br} \mathrm{J}$ Cancer 91: 519-524

Huang Z, Hankinson SE, Colditz GA, Stampfer MJ, Hunter DJ, Manson JE, Hennekens CH, Rosner B, Speizer FE, Willett WC (1997) Dual effects of weight and weight gain on breast cancer risk. JAMA 278: 1407-1411

Innes K, Byers T, Schymura M (2000) Birth characteristics and subsequent risk for breast cancer in very young women. Am J Epidemiol 152: 1121-1128

Kumle M, Weiderpass E, Braaten T, Persson I, Adami HO, Lund E (2002) Use of oral contraceptives and breast cancer risk: The NorwegianSwedish Women's Lifestyle and Health Cohort Study. Cancer Epidemiol Biomarkers Prev 11: 1375-1381

McCormack VA, dos Santos Silva I, De Stavola BL, Mohsen R, Leon DA, Lithell HO (2003) Foetal growth and subsequent risk of breast cancer: results from long term follow up of Swedish cohort. BMJ 326: 248
McCormack VA, dos Santos Silva I, Koupil I, Leon DA, Lithell HO (2005) Birth characteristics and adult cancer incidence: Swedish cohort of over 11,000 men and women. Int J Cancer 115: 611-617

Mellemkjaer L, Olsen ML, Sorensen HT, Thulstrup AM, Olsen J, Olsen JH (2003) Birth weight and risk of early-onset breast cancer (Denmark). Cancer Causes Control 14: 61-64

Michels KB, Trichopoulos D, Robins JM, Rosner BA, Manson JE, Hunter DJ, Colditz GA, Hankinson SE, Speizer FE, Willett WC (1996) Birth weight as a risk factor for breast cancer. Lancet 348: $1542-1546$

Michels KB, Xue F (2006) Role of birth weight in the aetiology of breast cancer. Int J Cancer 119: $2007-2025$

Michels KB, Xue F, Terry KL, Willett WC (2006) Longitudinal study of birth weight and the incidence of breast cancer in adulthood. Carcinogenesis Jun 15, epub ahead of print

Oken E, Gillman MW (2003) Foetal origins of obesity. Obes Res 11: 496-506

Sanderson M, Williams MA, Malone KE, Stanford JL, Emanuel I, White E, Daling JR (1996) Perinatal factors and risk of breast cancer. Epidemio$\log y$ 7: $34-37$

Titus-Ernstoff L, Egan KM, Newcomb PA, Ding J, Trentham-Dietz A, Greenberg ER, Baron JA, Trichopoulos D, Willett WC (2002) Early life factors in relation to breast cancer risk in postmenopausal women. Cancer Epidemiol Biomarkers Prev 11: 207-210

Troy LM, Michels KB, Hunter DJ, Spiegelman D, Manson JE, Colditz GA, Stampfer MJ, Willett WC (1996) Self-reported birth weight and history of having been breastfeed among younger women: an assessment of validity. Int J Epidemiol 25: $122-127$ 